\title{
Lasers and Lights by Gearge J. Hruza, Mathew M. Avram, Jefferey S Dover and Murad Alam
}

\author{
Jae-Gu Cho ${ }^{1}$ \\ Hwa Jung Ryu ${ }^{2}$
}

${ }^{1}$ Department of Otorhinolaryngology, College of Medicine, Korea University, Seoul, Korea

${ }^{2}$ Department of Dermatology, College of Medicine, Korea University, Seoul, Korea
(C) Korean Society for Laser Medicine and Surgery

(c) This is an open access article distributed under the terms of the Creative Commons Attribution NonCommercial License (http://creativecommons.org/ licenses/by-nc/3.0) which permits unrestricted noncommercial use, distribution, and reproduction in any medium, provided the original work is properly cited.
The book entitled 'Lasers and Lights' has been widely accepted as a 'must-read' for physicians who routinely treat patients with cosmetic lasers. It is not surprising that it already celebrates its $3^{\text {rd }}$ edition only 7 years after its birth in 2005.

One of the significant features of the $3^{\text {rd }}$ edition is the inclusion of case studies which present what physicians in the field routinely encounter while treating patients, in that any cases considered to be worthy of remark are highlighted with pearl. Furthermore, video

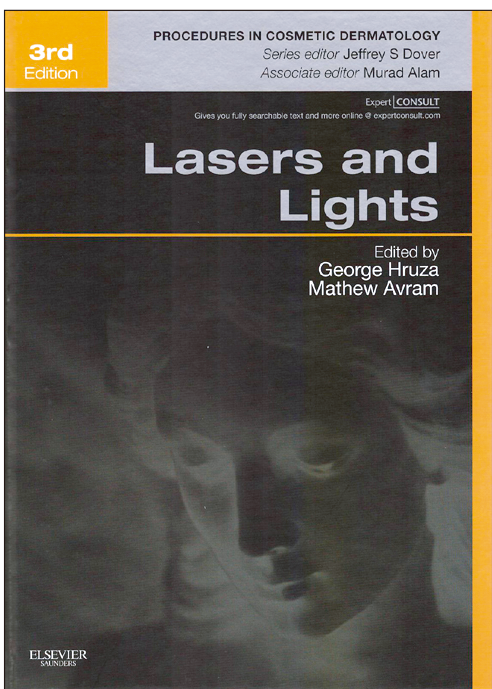
clips demonstrating the state-ofthe art techniques are also added in this edition, which provides a practical guidance to current techniques.

The authors Jeffrey S. Dover and Mural Alam indicated in the preface of the book that it is focused on therapeutic techniques with particular emphasis on discussing the treatment methods with an eye to appropriate indications, adverse events, and unusual cases. Since the cases are presented in a compact manner, it can be easily accessed as references whenever physicians need them for daily practice.

Chapters are organized to present the fundamental theory of laser, vascular laser, laser hair removal, laser treatment of pigmented lesions and tattoo, and use of laser for rejuvenation and tightening. In addition, a chapter is dedicated to the non-ablative fractional laser rejuvenation, which describes the significant development of the laser treatment since the concept of fractional photothermolysis was introduced to the field. The chapter entitled 'laser resurfacing' demonstrates that treatments using the $\mathrm{CO}_{2}$ and Er:YAG laser, 2,790 nm yttrium-scandium-gallium-garnet (Pear ${ }^{\circledR}$ ), plasma laser can produce remarkable therapeutic results, even though these techniques are now less frequently utilized than the more recently developed fractional laser.

A separate chapter is provided for treatment protocols for obesity as well as body contouring using non-invasive devices based on ultrasound or lights and laser for destroying fat. Techniques involving radiofrequency and laserassisted liposuction or cryolipolysis are also discussed in this chapter with the conclusion that these non-invasive protocols can improve appearance of fat and cellulite without downtime, even though liposuction is still widely 
practiced for the removal of a large volume of body fat.

The chapter entitled 'non-surgical skin tightening' introduces various devices which operate based on radiofrequency (Thermage is an example), vacuumassisted bipolar radiofrequency, infrared light, or HIFU (High-intensity focused ultrasound), and techniques that combine electrical and optical energy. However, in the end, it suggests that the most important factor to be considered in the clinical practice of non-surgical skin tightening procedures is to understand what patients want to select and how their expectations are managed hence make decisions based on that.

Practical tips and how to's for the treatment of ethnic skins are also provided in a separate chapter: an example is the tips on how to carefully use lasers when treating colored skin. The last chapter deals with complications arising from treatments using lights and lasers, and legal considerations associated with their utilization, which remind physicians of acting always in accordance with the standard of care with advices on cautions to be taken in clinical practice using cosmetic lights and lasers. 